GUIDELINES

\title{
Guidelines for management of patients with a short bowel
}

\author{
J Nightingale, J M Woodward on behalf of the Small Bowel and Nutrition Committee of the British \\ Society of Gastroenterology
}

\subsection{FORMULATION OF GUIDELINES 1.1 Aim \\ These guidelines aim to help clinicians manage patients who have had an intestinal resection that leaves a short length (about $2 \mathrm{~m}$ or less) of small bowel remaining.}

\subsection{Development}

The preliminary guidelines were compiled from the literature and a first document was drafted by Dr J Nightingale and modified by members of the Small Bowel and Nutrition Committee under the chairmanship of Dr B Jones. A section on "intestinal transplantation" was written by Dr Woodward and added with the approval of the Small Bowel and Nutrition Committee. The resulting document was shown to clinicians at the intestinal units of Hope and St Mark's Hospitals. Professor A Forbes made recommendations, which have been incorporated. The article was reviewed by the patient organisation PINNT (patients on intravenous or nasogastric nutritional therapy) and modifications made to result in the current document.

The guidelines conform to the North of England evidence based guidelines development project. ${ }^{1}$ The grading of each recommendation is dependant on the category of evidence supporting it.

Recommendations based on the level of evidence are presented and graded as:

- A: requires at least one randomised controlled trial of good quality addressing the topic of recommendation (evidence categories Ia and $\mathrm{Ib})$;

- B: requires the availability of clinical studies without randomisation on the topic of recommendation (evidence categories IIa, IIb and III); and

- C: requires evidence from expert committee reports or opinions or clinical experience of respected authorities in the absence of directly applicable clinical studies of good quality (evidence category IV).

See end of article for authors' affiliations .....................

Correspondence to: Dr J M D Nightingale, St Mark's Hospital, Harrow HA1 3UJ, UK; jeremy. nightingale@nwlh.nhs.uk

Received 25 January 2006 Accepted for publication 28 January 2006

\subsection{Scheduled review}

The content and evidence base for these guidelines should be reviewed within five years of publication. We recommend that these guidelines are audited and request feedback from all users.

\subsection{Service delivery}

Patients with a short bowel are not common but should be managed by a multidisciplinary team headed by a clinician with expertise in managing these patients. If managed appropriately, there
6;55(Suppl IV):iv1-iv12. doi: 10.1136/gut.2006.091108 may be an improved quality of safe care and also considerable cost savings. On occasions, patients thought to need long term parenteral nutrition may be weaned from it with appropriate advice.

As patients (particularly with a short bowel and jejunostomy) may rapidly become dehydrated or septic (if having parenteral nutrition), they and indeed any patient needing artificial nutritional support should have rapid access to medical expertise (advice, clinics, or inpatient treatment).

\subsection{Patients' experience}

- Patients with a short bowel should each be managed as an individual; they are all different in diagnosis, remaining bowel length/function, and psychosocial characteristics.

- Patients will become experts in coping with their condition and management. All decisions should all be made in conjunction with them. They are often more knowledgeable about their condition than the clinicians, nurses, and dieticians, and this should be respected.

- Facilities for looking after these patients should be able to deal with the physical, emotional, psychological, social, and quality of life issues.

- Techniques needed for home parenteral nutrition should be taught by competent, patient, and keen staff who can convey the confidence required to undertake the therapy successfully and safely.

- Patients need to know that the aseptic technique for parenteral nutrition will be used whenever their feeding line is accessed, which is vital for safety and peace of mind.

- Patients should be referred rapidly to places of expertise if management is difficult or unsuccessful. There should be clinicians, specialist nurses, and dieticians available to discuss or see the patients at all times. Healthcare professionals should be familiar to the patient and know their history, thus eliminating the need for time consuming explanations.

- There should ideally be dedicated beds for nutrition patients to ensure they are not cared for by healthcare professionals unfamiliar with their specialist needs.

- A 24 hour helpline should be in place so that emergencies are dealt with immediately and appropriately.

Abbreviations: PINNT, patients on intravenous or nasogastric nutritional therapy; IF, intestinal failure; GLP2 , glucagon-like peptide 2 
- Written and audiovisual material may help a patient cope, as will meeting other patients with similar problems.

- All patients who require home parenteral nutrition, whether short or long term, should receive information about the patient support group PINNT.

- Where appropriate, patients should be offered contact numbers for the relevant support group which represents their specific disease (for example, National Association for Colitis and Crohn's disease (NACC)).

- Follow up appointments should be as deemed appropriate to the multidisciplinary team and patient, and ideally the patient should not have to travel long distances for expert care. The appointment should be with experienced and familiar staff, thus enabling continuity of care.

- Staff should be aware of the latest research and developments and should make patients aware of any which may apply to them.

\subsection{SUMMARY OF RECOMMENDATIONS}

2.1 Aims of treatment in patients with a short bowel

- To provide the nutrition, water, and electrolytes necessary to maintain health, with normal body weight or growth.

- To use oral/enteral nutrition in preference to parenteral nutrition whenever the gut is functional and can absorb sufficient nutrients, water, and electrolytes.

- To reduce the complications resulting from the underlying disease, intestinal failure, and/or nutritional/fluid support.

- To achieve a good quality of life.

\subsection{Patients with a short bowel and an intact ileum and colon rarely need long term enteral or parenteral nutrition.}

2.3 Patients with a short bowel (due to loss of ileum) and a retained functional colon

Gradual undernutrition dominates the clinical picture. Due to adaptation, nutritional requirements may reduce with time.

- May need parenteral nutrition if less than $50 \mathrm{~cm}$ small intestine remains (grade B).

- Need a high carbohydrate low oxalate diet. The volume of food may increase diarrhoea (grade A).

\subsection{Patients with a jejunostomy}

Fluid and electrolyte losses dominate the clinical picture. Adaptation does not occur so nutritional and fluid requirements do not reduce with time.

- If less than $100 \mathrm{~cm}$ of jejunum remains, parenteral saline, and if less than $75 \mathrm{~cm}$, parenteral nutrition and saline are likely to be needed in the long term (grade B).

- If less than $200 \mathrm{~cm}$ of jejunum remains, oral hypotonic fluids may need to be restricted and a glucose-saline supplement (sodium concentration of about $100 \mathrm{mmol} / \mathrm{l}$ approximating to the concentration in jejunostomy fluid) is sipped to reduce stomal losses of sodium (grade B).

- Hypomagnesaemia is common and is treated by correcting sodium depletion, oral or intravenous magnesium supplements, and occasionally with oral 1 alpha hydroxycholecalciferol (grade C).

- Jejunal output may be further reduced by drugs that reduce motility (loperamide) or, if the bowel is very short (less than $100 \mathrm{~cm}$ ), drugs that reduce gastric acid secretion $\left(\mathrm{H}_{2}\right.$ antagonists, proton pump inhibitors, or somatostatin analogues) (grade $\mathrm{B}$ ).
Bowel length measurements are from the duodenojejunal flexure and can be made at surgery or with the use of an opisiometer ${ }^{2}{ }^{3}$ tracing out the long axis of the bowel on a contrast study that shows all of the remaining small bowel.

2.5 Patients with irreversible intestinal failure expected to die prematurely on parenteral nutrition should be referred for consideration of intestinal transplantation where appropriate

\subsection{INTRODUCTION TO INTESTINAL FAILURE AND SHORT BOWEL}

Intestinal failure (IF) occurs when there is reduced intestinal absorption so that macronutrient and/or water and electrolyte supplements are needed to maintain health and/or growth. ${ }^{4}$ If untreated, undernutrition and/or dehydration result. IF may be defined and quantified by balance study techniques; ${ }^{5}$ however, only few centres have the facilities for these difficult metabolic studies, and therefore nutrient/fluid requirements determine whether IF is termed severe, moderate, or mild (fig 1). Severe is when parenteral, moderate when enteral, and mild when oral nutritional fluid supplements are needed. ${ }^{6}$ A patient may change, due to compensatory mechanisms (for example, functional adaptation), from having severe to mild IF with time. IF can be acute or chronic (fig 2) and encompasses a wide variety of underlying medical and surgical conditions. Chronic IF most commonly results from a bowel resection that leaves a short residual length of small bowel.

Severe IF is a complex clinical and physiological situation that requires an experienced multidisciplinary input. These patients may be most appropriately managed in a centre with special interest and expertise in IF.

These guidelines aim to help practicing clinicians manage patients with IF due to a short bowel. Complications of the short bowel are covered but specific complications relating to therapy (for example, catheter related sepsis, hepatic or bone complications of parenteral nutrition) are not included. While bowel length is often unknown, patients who have had several ileal resections and have diarrhoea and weight loss may be treated as jejunum-colon patients, and patients with ileostomy diarrhoea, dehydration, hypomagnesaemia, and undernutrition may be treated as jejunostomy patients.

\subsection{SHORT BOWEL}

Normal human small intestinal length, measured from the duodenojejunal flexure at autopsy or surgery, varies from about $275 \mathrm{~cm}$ to $850 \mathrm{~cm}$, and tends to be shorter in women. After intestinal resection it is important to refer to the remaining length of small intestine measured at surgery or with an opisometer ${ }^{2}{ }^{3}$ rather than to the amount removed. In general, nutritional/fluid supplements are likely to be needed if less than $200 \mathrm{~cm}$ of small bowel remains.

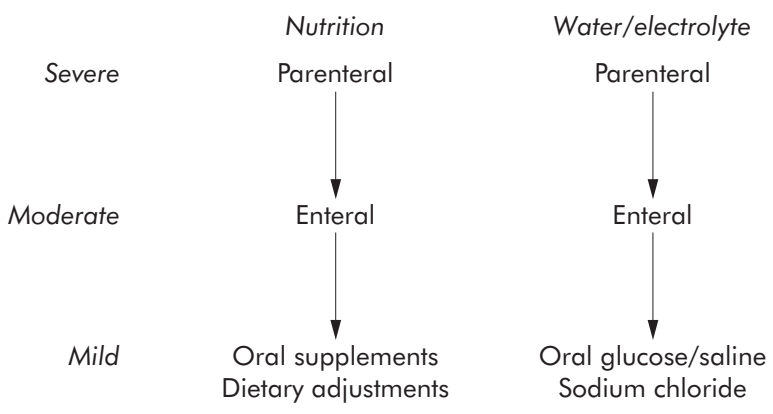

Figure 1 Severity of intestinal failure. Treatment aims to reduce the severity of intestinal failure. 


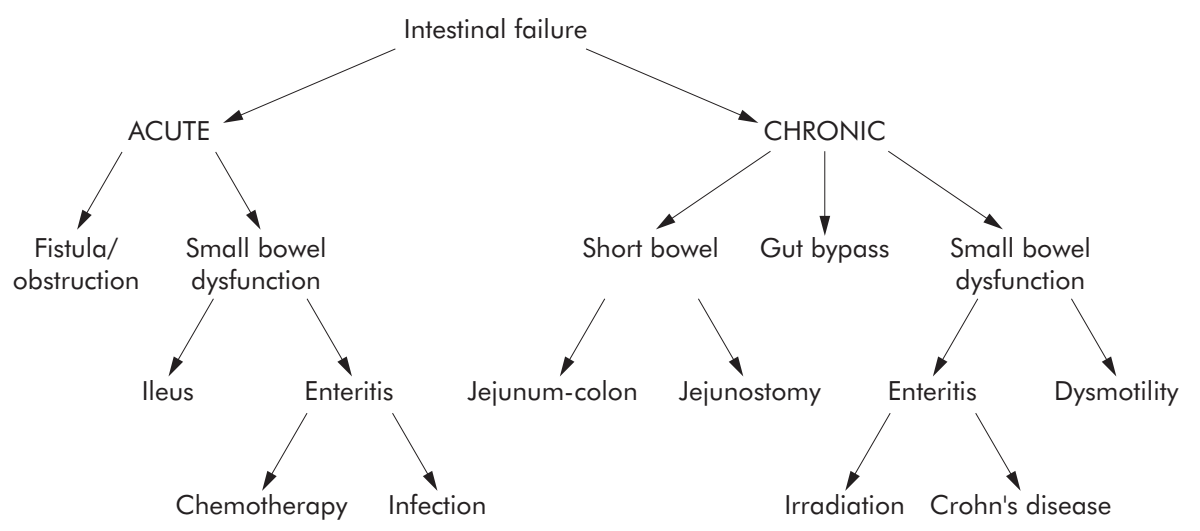

Figure 2 Reasons for intestinal failure.

There are three main types of patient with a short bowel: those who have had a jejunoileal resection and a jejunocolic anastomosis (jejunum-colon); those who have had a predominantly jejunal resection, and have more than $10 \mathrm{~cm}$ of terminal ileum and the colon remaining (jejunum-ileum); and those who have had a jejunoileal resection, colectomy, and formation of a stoma (jejunostomy). Jejunum-ileum patients are uncommon and rarely have problems of undernutrition and therefore do not often need nutritional support. When jejunum-ileum patients are seen, with undernutrition or severe diarrhoea after eating/drinking, they are managed in the same way as jejunum-colon patients. Jejunum-colon and jejunostomy patients are most commonly encountered. ${ }^{7-9}$ The most common reasons for a short bowel in adults are Crohn's disease, superior mesenteric artery thrombosis, and irradiation damage (table 1). ${ }^{3-9}$ A short bowel more commonly arises in women $(67 \%)$ than men, ${ }^{7}$ possibly because women start with a shorter length of small intestine than men.

Jejunum-colon patients often appear well after their resection except for diarrhoea/steatorrhoea, but in the following months may lose weight and become severely undernourished. Patients with a jejunostomy have problems of dehydration immediately after surgery due to large stomal water and sodium losses. This jejunal output is greatest after food and drink consumption.

\subsection{Physiological consequences}

The problems after major intestinal resection are due to both normal and altered physiology.

\subsubsection{Gastrointestinal motility}

Gastric emptying and small bowel transit for liquid is normal in jejunum-colon patients but fast in patients with a jejunostomy as the ileal and colonic braking mechanisms have been resected. ${ }^{10}$ This effect may be due to circulating plasma levels of peptide YY and glucagon-like peptide 2 (GLP-2) being high in those with a retained colon and low in jejunostomy patients. ${ }^{11-13}$

\begin{tabular}{ll} 
Table 1 Common causes of a short bowel \\
\hline Jejunum-colon & Jejunostomy \\
\hline Crohn's disease & Crohn's disease \\
Mesenteric ischaemia & Ulcerative colitis \\
Irradiation & Irradiation \\
Small bowel volvulus & Mesenteric ischaemia \\
Adhesions & Desmoid \\
\hline
\end{tabular}

\subsubsection{Gastrointestinal secretions}

Daily gastrointestinal secretions are made up of 0.5 litre of saliva, 2.0 litres of gastric juice, and 1.5 litres of pancreaticobiliary secretions plus passive jejunal secretions to render the lumen isotonic during passage and digestion of ingested nutrients. The majority of the fluid is reabsorbed in the upper jejunum. Jejunum-colon patients can reabsorb unabsorbed fluid in their colon but this is not the case for jejunostomy patients who lose much salt and water from their stoma. If less than $100 \mathrm{~cm}$ of jejunum remains proximal to a jejunostomy the patient may lose more fluid than is taken by mouth. ${ }^{14}$ Jejunal mucosa is "leaky" and rapid sodium fluxes occur across it. If water or any solution with a sodium concentration of less than $90 \mathrm{mmol} / \mathrm{l}$ is drunk there is a net efflux of sodium from the plasma into the bowel lumen, ${ }^{15}$ until a luminal sodium concentration of approximately $100 \mathrm{mmol} / \mathrm{l}$ is reached.

Gastric acid hypersecretion may occur in the first two weeks after a small bowel resection ${ }^{16}$ but there is no evidence that it occurs in the long term in humans.

\subsubsection{Absorptive functions}

Vitamin $\mathrm{B}_{12}{ }^{17}{ }^{18}$ and fat malabsorption ${ }^{19}$ occurs when more than $60-100 \mathrm{~cm}$ of terminal ileum have been resected. Increased hepatic synthesis of bile salts cannot compensate for the loss of ileal surface area. Unabsorbed bile salts may contribute to colonic secretion in patients with a remaining colon.

Magnesium deficiency occurs due to reduced absorption because of chelation with unabsorbed fatty acids in the bowel lumen $^{20}$ and to increased renal excretion (consequent on secondary hyperaldosteronism). ${ }^{21} 22$ Hypomagnesaemia reduces the secretion and function of parathormone, ${ }^{23}$ so directly increasing renal magnesium loss and indirectly by reducing the manufacture of 1,25 hydroxy-vitamin D which normally increases jejunal magnesium absorption. ${ }^{24}$

\subsubsection{Adaptative processes}

Patients with a short bowel do eat more food than normal (hyperphagia). ${ }^{25}$ Intestinal adaptation is the process that attempts to restore the total gut absorption of macronutrients, macrominerals, and water to that prior to intestinal resection. ${ }^{26}$ This occurs partly by increasing the absorptive area of the remaining bowel (structural adaptation) and/or by slowing gastrointestinal transit (functional adaptation).

\section{Jejunum-colon}

No definite structural intestinal adaptation has been demonstrated, ${ }^{27} 28$ even though high GLP-2 levels have been observed, ${ }^{12}$ although functional adaptation with slowing of gastric emptying and small bowel transit may occur ${ }^{10}$ 
probably due to high circulating peptide YY and GLP-2 levels. ${ }^{11}{ }^{12}$ There is increased jejunal absorption of macronutrients (for example, glucose), water, sodium, and calcium with time, ${ }^{29-32}$ and an increased chance of the patient being able to stop parenteral nutrition. ${ }^{37833}$ Thus these patients may show a gradual reduction in nutritional requirements with time.

\section{Jejunostomy}

Although intestinal adaptation occurs in the months after creation of an ileostomy, there is no evidence for any structural $^{34}$ or functional ${ }^{73}$ adaptation at any time in patients with a jejunostomy. Thus the nutritional and fluid needs of a patient with a jejunostomy are unlikely to change with time.

\subsection{Clinical assessment}

Clinical assessment of a patient with a short bowel includes assessment of water, sodium, magnesium, and nutritional status. Knowledge of residual small bowel length allows predictions to be made about the long term fluid/nutritional support that may be needed (table 2). The state of hydration and magnesium balance is of immediate importance to those with a jejunostomy.

Water and sodium deficiency (most common in jejunostomy patients) may result in thirst, hypotension, and prerenal failure. Daily body weight and accurate fluid balance (including stomal output) are the most important measurements. Serum creatinine, potassium, and magnesium, and urinary sodium may be measured every l-2 days initially, then once or twice a week and, if long term, at home every 23 months. Water and sodium deficiencies are detected by an abrupt fall in body weight, postural systolic hypotension, low urine volume and, if severe, by a rising serum creatinine and urea. The most helpful early measure of sodium depletion is the sodium concentration in a random urine sample. A concentration of less than $10 \mathrm{mmol} / \mathrm{l}$ suggests sodium depletion.

Magnesium depletion is common, especially in patients with a high stomal output. A serum value of less than $0.6 \mathrm{mmol} / \mathrm{l}$ may give rise to symptoms.

Current nutritional status may be assessed by recording the following (significantly low): body mass index $(<18.5 \mathrm{~kg} /$ $\mathrm{m}^{2}$ ), percentage weight loss $(<10 \%)$, or mid-arm muscle circumference $\left(<19 \mathrm{~cm}\right.$ in a woman, $<22 \mathrm{~cm}$ in a man). ${ }^{36} 37$

\subsection{PROBLEMS AND TREATMENT OF JEJUNUM- COLON PATIENTS}

Immediately following surgical resection that results in a short bowel, nutritional and fluid support are given, with parenteral nutrition being used early, even when enough bowel is thought to remain. This helps surgical repair, ileus recovery, and prevents vitamin/mineral deficiencies. Initially,

Table 2 Guide to bowel length and long term fluid/ nutritional support needed by patients with a short bowel 7 935

\begin{tabular}{lll}
\hline $\begin{array}{l}\text { Jejunal length } \\
(\mathbf{c m})\end{array}$ & Jejunum-colon & Jejunostomy \\
\hline $0-50$ & PN & PN+PS \\
$51-100$ & ON & PN+PS* \\
$101-150$ & None & ON+OGS \\
$151-200$ & None & OGS \\
\hline
\end{tabular}

$\mathrm{PN}$, parenteral nutrition; PS, parenteral saline ( \pm magnesium); $\mathrm{ON}$, oral (or enteral) nutrition; OGS, oral (or enteral) glucose/saline solution. ${ }^{*}$ At $85-100 \mathrm{~cm}$, may need PS only. a proton pump inhibitor is started and continued for six months as gastric acid hypersecretion may occur. ${ }^{38}$

In jejunum-colon patients the problems of undernutrition, diarrhoea due to malabsorption, and vitamin/mineral deficiencies dominate the clinical picture. These are the classical features initially described as constituting the "short bowel syndrome".

\subsection{Undernutrition: protein-energy malnutrition}

Undernutrition only becomes apparent slowly and should be prevented from occurring by predicting its likelihood and from knowledge of the residual length of bowel remaining (table 2). All patients who can be maintained on an oral diet need to consume more energy than normal subjects because $50 \%$ or more of the energy from the diet may be malabsorbed. Patients can achieve this by eating more high energy food, having oral sip-feeds, or high energy enteral feeds given at night through a nasogastric or gastrostomy tube. There are rarely any problems inserting a percutaneous endoscopic gastrostomy (PEG) into patients with Crohn's disease providing that there is no distal obstruction. ${ }^{39}$ Once weight is regained, a nocturnal feed can be reduced or stopped and sip-feeds during the day may be adequate. Only if these measures fail and the patient continues to lose weight, or fails to regain lost weight, is parenteral nutrition given. Parenteral nutrition may only be needed for a few weeks or months before oral supplements are adequate.

In the long term, parenteral nutrition is needed if a patient absorbs less than one third of the oral energy intake, ${ }^{14} 40$ if there are high energy requirements and absorption is 30$60 \%$, or if increasing oral/enteral nutrient intake causes a socially unacceptably amount of diarrhoea or a large volume of stomal output.

In jejunum-colon patients, unabsorbed long chain fatty acids in the colon are likely to reduce transit time ${ }^{41}$ and reduce water and sodium absorption ${ }^{42}$ so making diarrhoea worse. In addition, they are toxic to bacteria and so reduce carbohydrate fermentation. ${ }^{43}$ They bind to calcium and magnesium, increasing stool losses, and they increase oxalate absorption so predisposing to the formation of renal stones (see below).

Theoretically, a low fat diet is ideal for patients after a small bowel resection ${ }^{44}$ but in practice it is hard to implement. Fat yields twice as much energy as comparable weights of carbohydrate and makes food more palatable. A high carbohydrate/low fat diet involves eating a large volume of food. A low fat diet may increase calcium, magnesium, and zinc absorption ${ }^{20}{ }^{45}$ but makes essential fatty acid deficiency more likely. ${ }^{46}$ Sunflower oil may be rubbed into the skin to ensure adequate amounts of essential fatty acids enter the body. ${ }^{47}$ If a diet is high in monosaccharides D (-) lactic acidosis may occur (see 5.5). Medium chain triglycerides are an alternative source of energy and are absorbed from the small and large bowel. ${ }^{48-51}$

In order to increase energy absorption and reduce the risk of renal stones and D-lactic acidosis, patients with a retained colon need a large total energy intake with a diet high in carbohydrates (polysaccharides), ${ }^{52}$ normal (not restricted) in fat (long chain triglycerides), and low in oxalate.

\subsubsection{Conjugated bile acid treatment}

Cholylsarcosine has been used as bile acid replacement therapy but with variable improvement in fat and calcium absorption. ${ }^{53} 54$ There is little evidence for its use.

\subsection{Salt, water, and magnesium depletion}

The colon has a large capacity to absorb sodium and water; thus patients with a short bowel and a preserved colon are rarely in negative water and sodium balance and rarely need water or sodium supplements. ${ }^{7556}$ Although the colon 
secretes potassium, a low serum potassium level rarely occurs. $^{7}$

If sodium depleted, a glucose-saline drink can be sipped during the day, as for patients with a jejunostomy. A low serum magnesium is less common than in patients with a jejunostomy ${ }^{7}$ but is treated in the same way.

\subsection{Vitamin and mineral deficiencies}

Most patients require long term $\mathrm{B}_{12}$ treatment. ${ }^{17}{ }^{18}$ Selenium deficiency is common and patients may need larger amounts than normal subjects. ${ }^{57-60}$ Zinc deficiency is uncommon unless stool volumes are large. ${ }^{61}$ Vitamins A, D, E, and $\mathrm{K}$, and essential fatty acids may need to be replaced.

\subsection{Diarrhoea}

Oral intake determines the volume of stool passed, so limiting food intake will reduce diarrhoea but will exacerbate the problems of undernutrition. A patient may require parenteral nutrition to allow them to eat less and so reduce their diarrhoea.

Diarrhoea is treated in the same way as for patients with a jejunostomy, with loperamide $2-8 \mathrm{mg}$ given half an hour before food and occasionally codeine phosphate is also added (30-60 mg half an hour before food).

If $100 \mathrm{~cm}$ or more of terminal ileum have been resected, bile salt malabsorption may contribute to diarrhoea and occasionally this is helped by cholestyramine. Cholestyramine has the additional advantage of reducing oxalate absorption, but by further reducing the bile salt pool will increase fat malabsorption. ${ }^{62}$ Although gastric antisecretory drugs may reduce diarrhoea shortly after surgery, they may not be effective in the long term.

\subsection{Confusion}

In addition to the many common general medical causes of confusion (for example, hypoxia, hepatic, renal or cardiac failure, sepsis, hypoglycaemia, alcohol, or other drugs), other specific causes should be sought in a patient with a short bowel. Hypomagnesaemia may cause mild confusion when the serum magnesium level is very low (less than $0.2 \mathrm{mmol} /$ 1). Thiamine deficiency can cause a Wernicke/Korsikoff psychosis which responds rapidly to large regular doses of thiamine. Two other specific causes of confusion in patients with a short bowel are $\mathrm{D}(-)$ lactic acidosis and hyperammonaemia.

$\mathrm{D}(-)$ lactic acidosis only occurs in patients with a short bowel and a preserved colon. Colonic bacteria may degrade a surplus of fermentable carbohydrate to form $\mathrm{D}(-)$ lactate which is absorbed but not easily metabolised. ${ }^{63}$ In addition to a metabolic acidosis with a large anion gap, increased concentrations of $\mathrm{D}(-)$ lactate are found in blood and urine. Treatment involves restricting mono and oligosaccharides ${ }^{64}$ and encouraging the more slowly digestible polysaccharides (starch), thiamine supplements, and broad spectrum antibiotics. In rare cases the patient may need to fast while receiving parenteral nutrition.

Confusion may be due to hyperammonaemia (also occurs in jejunostomy patients); this results because ammonia cannot be detoxified. The small amount of intestine remaining cannot manufacture adequate citrulline to detoxify ammonia via the urea cycle. The increase in blood ammonia is a problem if there is concomitant renal impairment, as the excess ammonia cannot be excreted. By giving arginine (an intermediary in the urea cycle), hyperammonaemia can be corrected..$^{65}$

\subsection{Drug absorption}

Omeprazole can be absorbed in the duodenum/upper jejunum and only if less than $50 \mathrm{~cm}$ of jejunum remains are problems likely to occur. Many drugs will be incompletely absorbed by patients with a short bowel and may be needed in much higher amounts than usual (for example, thyroxine, warfarin, ${ }^{67}$ and digoxin ${ }^{68}$ ) or may need to be given intravenously. If a patient is taking warfarin, blood for the international normalised ratio should be taken at the same time of day relative to a lipid infusion. As the enterohepatic circulation, around which loperamide circulates, is disrupted, higher doses than usual may need to be given.

\subsection{Gall stones}

Gall stones are common (45\%) (same prevalence in jejunostomy patients) and are more common in men. ${ }^{7}$ Such stones probably result from gall bladder stasis in which biliary sludge develops and subsequently forms calcium bilirubinate stones.

Therapies to prevent the formation of biliary sludge and hence gall stones include periodic intravenous infusions of amino acids $^{69}$ or enteral feed, cholecystokinin injections, ${ }^{70}$ non-steroidal anti-inflammatory drugs, ${ }^{71}{ }^{72}$ ursodeoxycholic acid, $^{73}$ and reducing the formation of the more lithogenic secondary bile acids by either increasing bowel transit ${ }^{74}$ or by inhibiting bowel bacteria (for example, metronidazole). ${ }^{75}$ Some units advocate prophylactic cholecystectomy whenever a large resection of the small intestine is performed. ${ }^{76}$

\subsection{Renal stones}

Jejunum-colon patients have a $25 \%$ chance of developing symptomatic calcium oxalate renal stones. ${ }^{7}$ Calcium oxalate precipitation in the renal tract may form discrete stones or less commonly a diffuse nephrocalcinosis, which may lead to chronic renal failure. The stones result from increased colonic absorption of dietary oxalate especially ${ }^{77-81}$ Factors contributing to calcium oxalate renal stone formation include fat malabsorption, increased bile salt induced colonic permeability to oxalate, reduced bacterial degradation of oxalate, pyridoxine or thiamine deficiency, and hypocitraturia. ${ }^{82}$

To prevent calcium oxalate renal stone formation, patients should avoid dehydration and take a diet low in oxalate. A low oxalate diet means avoiding foods such as spinach, rhubarb, beetroot, nuts, chocolate, tea, wheat bran, and strawberries ${ }^{8183}$ Other measures to reduce calcium oxalate stone formation include reducing dietary fat ${ }^{77}$ 80 $^{84-86}$ or replacing with medium chain triglycerides, ${ }^{84}$ and increasing dietary calcium ${ }^{85-87}$; and oral cholestyramine administration may $^{7888}$ or may not ${ }^{85}$ help.

\subsection{Social problems}

Most long term patients with a short bowel have a normal body mass index and are in full time employment or look after their home and family unaided. ${ }^{7}$ Jejunum-colon patients may have diarrhoea, which is malodorous and bulky due to steatorrhoea.

\subsection{PROBLEMS AND TREATMENT OF JEJUNOSTOMY PATIENTS}

The major differences between jejunum-colon and jejunostomy patients are that jejunostomy patients lose much salt and water from their stoma, commonly have hypomagnesaemia but they do not have significant bacterial fermentation occurring in the bowel lumen. Many other problems are similar (e.g. $\mathrm{B}_{12}$ deficiency, confusion, drug absorption and gall stones).

\subsection{Salt and water depletion}

Patients with a jejunostomy have a large volume of stomal output, which is greater after eating or drinking. Each litre of jejunostomy fluid contains about $100 \mathrm{mmol} / \mathrm{l}$ of sodium. ${ }^{14}$

The effluent from a jejunostomy or ileostomy contains relatively little potassium (approximately $15 \mathrm{mmol} / \mathrm{l}$ ). ${ }^{1455} 56$ Potassium balance is not often a problem and net loss 
Table 3 Summary of management of a patient with a jejunostomy*

- Exclude/treat causes other than a short bowel (for example, infection (intra or extraluminal), partial obstruction, abrupt stopping of drugs) (grade C)

- Correct dehydration with intravenous saline while the patient takes nothing by mouth for $24-48$ hours. This stops thirst and thus the desire to drink (grade C)

- Reduce oral hypotonic fluids to $500 \mathrm{ml} /$ day. This is the most important measure (grade B)

- Give glucose/saline solution to sip (sodium concentration at least $90 \mathrm{mmol} / \mathrm{l}$ ). Most stomal/fistula losses (except from the colon) have a sodium concentration of about $100 \mathrm{mmol} / \mathrm{l}$ (grade B)

- Add sodium chloride to any liquid feeds to make the sodium concentration near to $100 \mathrm{mmol} / \mathrm{I}$ while keeping osmolality near $300 \mathrm{mosmol} / \mathrm{kg}$ (grade B)

- Give drugs to reduce motility; loperamide 2-8 mg (non-sedative and non-addictive) before food. Occasionally, addition of codeine phosphate further reduces stomal output (grade B)

- If there is net "secretory" output (generally more than $3 \mathrm{l} / 24$ hours), drugs that reduce gastric acid secretion $\left(\mathrm{H}_{2}\right.$ antagonists or proton pump inhibitors) or if unable to absorb oral drugs, octreotide can reduce stomal output by $1-2 \mathrm{l} / 24$ hours (grade A)

- Other measures include:

Separating solids and liquids (that is, having no drink for half an hour before or after food) (grade C)

Using salt capsules instead of glucose/saline solution (grade B)

A trial of fludrocortisone if the ileum remains (grade B)

- Correct hypomagnesaemia (see table 6)

Intravenous magnesium sulphate initially then oral magnesium oxide and/or 1-alpha cholecalciferol (grade B)

${ }^{*}$ The same management applies for management of high output enterocutaneous fistula (providing there is no ongoing intra-abdominal sepsis) and for "ileostomy diarrhoea".

through the stoma occurs only when less than $50 \mathrm{~cm}$ of jejunum remains. ${ }^{14}$ A low serum potassium level is most commonly due to sodium depletion with secondary hyperaldosteronism and thus greater than normal urinary losses of potassium. ${ }^{55}$ Hypokalaemia can also be due to hypomagnesaemia, which causes dysfunction of many of the potassium transport systems and increases renal potassium excretion; this hypokalaemia is resistant to potassium treatment but responds to magnesium replacement..$^{89}$

\subsubsection{Management of a high output jejunostomy/ ileostomy (table 3)}

It is helpful both in predicting outcome and in choosing the type of nutritional support if the remaining length of bowel is known. Contrast studies (small bowel meal or enema) may help. Examination of the output (colour/consistency/24 h volume) may also give an indication of the type of stoma. The principles described here are the same for a high output ileostomy.

\section{Exclude other causes of a high output}

A stoma may produce a high output if there is intraabdominal sepsis, partial/intermittent bowel obstruction, enteritis (for example, clostridium or salmonella), recurrent disease in the remaining bowel (for example, Crohn's disease or irradiation), suddenly stopping drugs (for example, steroids or opiates), or giving prokinetics (for example, metoclopramide).

\section{Treatment of a high output jejunostomy}

If there is marked sodium and water depletion and severe thirst, it is often necessary to establish equilibrium by giving

\begin{tabular}{|c|c|}
\hline \multicolumn{2}{|c|}{ Modified WHO cholera rehydration solution } \\
\hline Sodium chloride & $60 \mathrm{mmol}(3.5 \mathrm{~g})$ \\
\hline Sodium bicarbonate (or citrate) & $30 \mathrm{mmol}(2.5 \mathrm{~g})(2.9 \mathrm{~g})$ \\
\hline Glucose & $110 \mathrm{mmol}(20 \mathrm{~g})$ \\
\hline Tap water & 1 litre \\
\hline \multicolumn{2}{|l|}{ Alternative rehydration solution } \\
\hline Sodium chloride & $120 \mathrm{mmol}(7 \mathrm{~g})$ \\
\hline Glucose & $44 \mathrm{mmol}(8 \mathrm{~g})$ \\
\hline Tap water & 1 litre \\
\hline
\end{tabular}

intravenous normal saline (2-4 l/day), keeping the patient "nil by mouth", which will also demonstrate that output is driven by their oral intake. Over 2-3 days intravenous saline is gradually withdrawn while food and restricted oral fluids are reintroduced. Great care must be taken not to administer too much fluid, which will readily cause oedema (partly due to high circulating aldosterone levels)..$^{55}$ The aims of treatment are to maintain hydration/body weight and a daily urine volume of at least $800 \mathrm{ml}$ with a sodium concentration greater than $20 \mathrm{mmol} / \mathrm{l}$.

To correct hypokalaemia in patients with a high output stoma, sodium/water depletion must be corrected, and serum magnesium brought into the normal range. It is uncommon for potassium supplements to be needed.

Restrict oral fluids. It is a common mistake for patients to be encouraged to drink oral hypotonic solutions to quench their thirst but this causes large stomal sodium losses. ${ }^{91-96}$ Hypertonic fluids, which may contain sorbitol or glucose, can also cause stomal losses of water and sodium. Treatment for high output from a jejunostomy (ileostomy or high fistula) begins with the patient restricting the total amount of oral hypotonic fluid (water, tea, coffee, fruit juices, alcohol, or dilute salt solutions) and also of hypertonic fluids (fruit juices, Coca cola, and most commercial sip feeds)to less than $500 \mathrm{ml}$ daily. To make up the rest of the fluid requirement, the patient is encouraged to drink a glucose-saline replacement solution ( $90 \mathrm{mmol} / \mathrm{l}$ sodium or more) (table 4 ). Many patients at home with marginally high stoma outputs (11.5 litres) will be helped by a combination of oral fluid restriction (less than 1 litre per day) and addition of salt to their diet.

Often patients are advised to take liquids and solids at different times (no liquid for half an hour before and after food) however there is no published evidence that this reduces stomal output or increases macro or micronutrient absorption. ${ }^{97}$

Drink oral glucose-saline solution. Patients with stomal losses of less than $1200 \mathrm{ml}$ daily can usually maintain sodium balance by adding extra salt to the limit of palatability at the table and when cooking. When stoma losses are in the range 1200-2000 ml, or sometimes more, it is possible for a patient to maintain sodium balance by taking a glucose-saline solution or salt capsules. ${ }^{94}{ }^{96}$ In hot weather, due to water and sodium loss in sweat, patients with a stoma are more likely to have problems of dehydration. 
As the sodium content of jejunostomy (or ileostomy) effluent is relatively constant at approximately $90 \mathrm{mmol} / \mathrm{l}$ and as there is coupled absorption of sodium and glucose in the jejunum, ${ }^{98-100}$ patients are advised to sip a glucose-saline solution with a sodium concentration of at least $90 \mathrm{mmol} / \mathrm{l}$ throughout the day. The World Health Organization (WHO) cholera solution has a sodium concentration of $90 \mathrm{mmol} / \mathrm{l}^{101}$ and is commonly used (without the potassium chloride) (table 4). This concentration of sodium in this solution is much higher than many commercial preparations used to treat infective or traveller's diarrhoeas. Alternative solutions include replacing sodium bicarbonate with sodium citrate to increase palatability or giving a glucose polymer mixture to allow more energy absorption (over $100 \mathrm{kcal} / 24 \mathrm{~h}$ ). ${ }^{96}$

The patient is encouraged to sip a litre or more of one of these solutions in small quantities throughout the day. To improve palatability the solution may be chilled or flavoured with fruit juice.

Sodium chloride capsules (500 mg each) are effective when taken in large amounts (14/24 h) but can cause some patients to feel sick and even vomit. ${ }^{96}$ If an enteral feed is given, sodium chloride needs to be added to make the total sodium concentration of the feed $100 \mathrm{mmol} / \mathrm{l}$ while keeping osmolality near to $300 \mathrm{mosmol} / \mathrm{kg}$.

Drug therapy. If restricting oral fluids and giving a glucosesaline solution to drink are not adequate drugs may be needed. As the intestinal output, especially in net "secretors" rises after meals, it is important to give the drugs before food. Drugs used to reduce jejunostomy output act to reduce either intestinal motility or secretions.

\section{- Antimotility (antidiarrhoeal) drugs}

Loperamide and codeine phosphate reduce intestinal motility and thus decrease water and sodium output from an ileostomy by approximately $20-30 \% .^{100-104}$ Loperamide is preferred to opiate drugs (for example, codeine phosphate) as it is not sedative, addictive, and does not cause fat malabsorption. ${ }^{103} 105$

Oral loperamide $4 \mathrm{mg}$ taken four times a day was more effective in reducing the weight and sodium content of ileostomy fluid than codeine phosphate $60 \mathrm{mg}$ taken four times a day ${ }^{103}$ but the effect of both together may be greater. ${ }^{106}$ Loperamide circulates through the enterohepatic circulation, which is severely disrupted in patients with a short bowel, and small bowel transit may be very rapid. Thus high doses of loperamide (for example, 12-24 mg at a time) may be needed. Lomotil is occasionally used but anticholinergic effects (for example, dry mouth) may be a problem.

If these or any tablets/capsules emerge unchanged in stool/ stomal output, they can be crushed, opened, mixed with water, or put on food.

\section{- Antisecretory drugs}

Drugs that reduce gastric acid secretion (for example, the $\mathrm{H}_{2}$ antagonists or proton pump inhibitors or the somatostatin analogue octreotide) are most commonly used.

Cimetidine (400 mg orally or intravenously four times a day), ${ }^{105} 106$ ranitidine (300 mg orally twice daily), ${ }^{14}$ and omeprazole (40 mg orally once a day or intravenously twice a day $)^{109}{ }^{110}$ reduce jejunostomy output, particularly in those with a net secretory output and generally in those with an output exceeding 2 litres daily. Omeprazole is readily absorbed in the duodenum and upper small bowel, but if less than $50 \mathrm{~cm}$ of jejunum remains, it may need to be given intravenously (some units administer it orally with sodium bicarbonate). These drugs, which inhibit gastric acid secretion, are as effective as octreotide $(50 \mu \mathrm{g}$ subcutaneously twice daily) in reducing the volume of stomal output. ${ }^{14} 109$ They do not change the absorption of energy, carbohydrate, lipid, nitrogen, or divalent cations, ${ }^{107-110}$ and do not reduce jejunostomy output enough to reduce the severity of IF (that is, prevent the need for parenteral fluid and electrolyte replacement).

In adults, octreotide reduces ileostomy diarrhoea and large volume jejunostomy output. ${ }^{111-119}$ The greatest reductions in intestinal output are in those with a net secretory output, and the volume of parenteral supplements needed may be reduced. ${ }^{115-119}$ The reduction in sodium output parallels that of intestinal output ${ }^{111-119}$ while magnesium balance is unchanged. ${ }^{112}{ }^{117}$ Total energy ${ }^{115} 118119$ and nitrogen ${ }^{111} 113$ 117-119 absorption are not significantly changed while fat absorption may be unchanged ${ }^{117-119}$ or reduced. ${ }^{112}$ The effect of octreotide is maintained in the long term. ${ }^{12} 114115117119$ Long acting octreotide/somatostatin preparations have not been assessed in large studies ${ }^{120}$ but may prove to be effective in the future.

Mineralocorticoids (for example, $2 \mathrm{mg}$ oral fludrocortisone or $2 \mathrm{mg}$ intravenous d-aldosterone) $)^{121-123}$ or high dose hydrocortisone ${ }^{124}$ may reduce stomal output in patients with a retained ileum.

Intravenous therapy. Some patients will not maintain hydration with the above measures and intravenous or subcutaneous saline may be needed. Half to one litre of saline may be given subcutaneously (with $4 \mathrm{mmol}$ magnesium sulphate) if only needed $1-3$ times a week ${ }^{125}$ and intravenously if more frequently. An intravenous line is likely to be a tunnelled cuffed (long term) central line through which a parenteral feed can also be given if undernutrition is or is likely to be a problem. The saline bag may have 4-12 $\mathrm{mmol}$ magnesium sulphate added.

\subsection{Hypomagnesaemia (table 5)}

Rehydration to correct secondary hyperaldosteronism is the most important first step. Most magnesium salts are poorly absorbed and may worsen diarrhoea/stomal output. Magnesium oxide is commonly given and contains more elemental magnesium than other salts, is insoluble in water and alcohol, but soluble in dilute acid. In the stomach it is converted to magnesium chloride. It is given as gelatine capsules of $4 \mathrm{mmol}$ magnesium oxide ( $160 \mathrm{mg}$ of $\mathrm{MgO}$ ) to a total of 12-24 mmol daily. Magnesium oxide is usually given at night when intestinal transit is assumed to be slowest and hence there is more time for absorption.

If oral magnesium supplements do not normalise magnesium levels, oral 1-alpha hydroxy-cholecalciferol in a gradually increasing dose (every 2-4 weeks) of 0.25-9.00 $\mu \mathrm{g}$ daily may improve magnesium balance ${ }^{125} 126$ bit regular monitoring of serum calcium is necessary to avoid hypercalcaemia.

Occasionally magnesium is given as an intravenous or subcutaneous infusion, usually with saline. ${ }^{125}$

\subsection{Undernutrition: protein-energy malnutrition}

Patients with a jejunostomy absorb a constant proportion of the nitrogen, energy, and fat from their diet. ${ }^{45}{ }^{52}{ }^{128}$ Increasing

\section{Table 5 Prevention/treatment of hypomagnesaemia}

(1) Correct water and sodium depletion (thus secondary hyperaldosteronism) (grade C)

(2) Oral magnesium preparation (for example, $12 \mathrm{mmol}$ magnesium oxide at night) (grade C)

(3) Reduce/avoid excess lipid in diet (grade C)

(4) Oral 1 alpha cholecalciferol (0.25-9.00 $\mu \mathrm{g}$ daily) (grade C)

(5) Intravenous magnesium (occasionally subcutaneous or intramuscular magnesium sulphate) (grade C) 


\begin{tabular}{lll} 
Table 6 Summary of the problems of a short bowel & \\
\hline & Jejunum-colon & Jejunostomy \\
\hline Presentation & $\begin{array}{l}\text { Gradual, diarrhoea and } \\
\text { undernutrition }\end{array}$ & Acute fluid losses \\
Water, sodium, and magnesium & Uncommon in the long-term & Common \\
depletion & Common* & \\
Nutrient malabsorption & Occasionally & Very common \\
D (-) lactic acidosis & $25 \%$ & None \\
Renal stones (calcium oxalate) & $45 \%$ & None \\
Gall stones (pigment) & Functional adaptation & No evidence \\
Adaptation & Diarrhoea & High stomal output dehydration \\
Social problems & & dependency on treatment \\
& &
\end{tabular}

*Bacterial fermentation of carbohydrate salvages some energy, but D (-) lactic acidosis can occur if the diet is high in mono and oligosaccharides.

fat in the diet increases energy density, keeps the diet osmolality low, increases palatability, and provides essential fatty acids. ${ }^{46}$ It does raise fat excretion but does not usually increase stomal output, nor make output offensive. ${ }^{45} 52128$

There is no advantage in giving a diet of small molecules (for example, an elemental diet), which causes a feed to be hyperosmolar ${ }^{128}$ and usually contains little sodium, so stomal losses of water and sodium increase. As stomal sodium losses are approximately $100 \mathrm{mmol} / \mathrm{l}$, any diet will need added sodium chloride.

These patients need a diet of high energy (carbohydrate or lipid) in which osmolality is kept low using large molecules (polysaccharides, protein, and triglycerides) ) $^{128} 129$ and to which sodium chloride is added to give the meal/liquid feed a total sodium concentration of $90-120 \mathrm{mmol} / \mathrm{l}$ and an osmolality of approximately $300 \mathrm{mosmol} / \mathrm{kg}$.

\subsection{Social problems}

Effluent from a small bowel stoma, unlike from a colostomy, is not offensive but large volumes of fluid may cause practical difficulties with emptying the bag and embarrassment with occasional leakage.

A summary of the problems of a short bowel are given in table 6.

\subsection{ALTERNATIVE TREATMENTS}

\subsection{Growth factors}

Four randomised placebo controlled studies have been performed using growth hormone to stimulate mucosal growth. ${ }^{130-133}$ In three studies there was no significant increase in absorption but one showed a small improvement in nutrient absorption. ${ }^{133}$ As plasma levels of GLP-2, which causes villus growth, are low in patients with a jejunostomy, ${ }^{13}$ GLP-2 has been given as a subcutaneous injection and a small increase in nutrient absorption occurred. ${ }^{134}$ An analogue of GLP-2 that is resistant to degradation (teduglutide) has shown a more pronounced effect in increasing intestinal fluid absorption, and drug induced mucosal growth was demonstrated for the first time in humans. ${ }^{135}$

\subsection{Surgical treatments}

Surgical treatments other than transplantation have tried to slow intestinal transit or increase the surface area for absorption. Favourable results have been reported from reversal of a $10 \mathrm{~cm}$ segment of small intestine. ${ }^{136}{ }^{137}$

\subsection{Intestinal transplantation}

Transplantation has now become a standard operation for end stage liver, kidney, heart, or lung failure. Intestinal transplantation is possible for patients with IF and over 1200 such operations have now been performed worldwide. In many cases the patient may require a liver-small bowel graft or a "multivisceral" graft, including other organs such as the stomach and pancreas. Unlike renal failure, where transplantation is preferable to long term extracorporeal support, intestinal transplantation cannot yet be recommended as an alternative therapy for patients stably maintained on intravenous nutrition. This is due both to the excellent outcomes reported overall for long term parenteral nutrition ${ }^{138-145}$ and the challenges posed by intestinal transplantation. ${ }^{146}$ The intestine is a difficult organ to transplant due to its immunogenicity, large population of donor immune cells present within the graft, and its nonsterile contents. Rejection causes barrier failure and bacterial translocation so that sepsis may occur at a time when increased immunosuppression is required and the patient may rapidly become too unwell to consider graft removal. Significant recent advances have made intestinal transplantation a more acceptable procedure. The development of tacrolimus based immunosuppressive regimens in the 1990s more than doubled the number of survivors following intestinal transplantation compared with the use of ciclosporin in the previous decade. The resulting increase in lymphoproliferative disease resulting from heavy non-specific immunosuppression has led to revision of immunosuppressive regimens over the last few years, with further benefits in patient outcome due to the use of antilymphocyte induction therapy. Furthermore, while it was considered an option of last resort, initially only the sickest patients were transplanted with predictably poor results-identifying patients likely to benefit from transplantation and offering the operation at an earlier stage in the disease results in improved survival. ${ }^{147}$

Intestinal transplantation is currently associated with approximately $80 \%$ one year survival and approaching $50 \%$ five year survival, with the majority of survivors being free of parenteral nutrition. ${ }^{147}$ Studies indicate a considerable increase in the quality of life following transplantation, which has been found to be better than for patients on long term parenteral nutrition with complications of therapy, and equivalent to that of patients with uncomplicated IF. ${ }^{148}$ Direct comparison of the results of intestinal transplantation with long term survival rates on home parenteral nutrition are invalid, as transplantation is only currently considered for selected patients likely to experience a poor outcome on intravenous feeding. Clearly, patients with IF comprise a heterogeneous group and only recently have attempts been made to identify those patients that have impaired survival while receiving long term parenteral nutrition. Those most at risk of poor outcomes on parenteral nutrition include patients with very short residual small intestinal length $(<50 \mathrm{~cm})$, those with an end jejunostomy, and patients with motility disorders. ${ }^{149}$ 
Table 7 Current indications for referral of adults to an intestinal transplantation centre in the UK

Complications of parenteral nutrition

- Liver disease (portal hypertension, bridging hepatic fibrosis, or cirrhosis) due to parenteral nutritionirreversible despite referral and management by an established parenteral nutrition centre.

- Progressively compromised vascular access for parenteral feeding-loss of all but two major venous access points (one of which should be above the diaphragm).

- Recurrent or life threatening central line sepsis (including fungal sepsis).

- Inadequate maintenance on parenteral nutrition for any other reason-for instance, inability to manage hydration/nutrition status despite parenteral nutrition.

High risk conditions

- Requirement for extensive evisceration (that is, desmoid tumours, trauma, rare selected malignancies including neuroendocrine tumours)

Most deaths of parenterally fed patients are attributable to the underlying disease and with some exceptions (for instance, liver and small bowel transplantation for mesenteric infarction due to an inherited thrombophilic disorder), the deaths preventable by transplantation are those caused by complications of long term parenteral nutrition. These include infection related to the indwelling venous feeding catheter accounting for up to $70 \%$ of parenteral nutrition related deaths, 139141143150151 thrombosis precluding adequate access for feeding, ${ }^{152-155}$ and liver complications. ${ }^{156-159}$ Certain types of patients appear to be at increased risk of line related sepsis, including those requiring high doses of opiates on a regular basis and those with a stoma. ${ }^{150} 160161$ Unfortunately, life threatening infections occur stochastically, and while it might be logical to consider that those with frequent line related sepsis are at increased risk of such an event, current data do not support a worse outcome for such patients. Similarly, venous thromboses and occlusions preventing adequate access occur infrequently ${ }^{154}$ and it is impossible to predict the rate at which loss of vascular access may occur. The extent to which serious liver complications occur as a result of parenteral nutrition is controversial. Alterations in biochemical liver function are common, ${ }^{156-158} 162163$ but the proportion of parenteral nutrition related deaths attributable to liver disease varies in adults from $0 \%{ }^{162}$ to $22 \% .{ }^{163}$ Identification of those groups of patients at most risk of major complications on parenteral nutrition and likely to benefit from intestinal transplantation therefore remains a high research priority.

Adult intestinal transplantation in the UK is carried out in two national centres-at Addenbrooke's Hospital in Cambridge and in St James' Hospital in Leeds, linked respectively to the Intestinal Failure Units at St Mark's and the Hope Hospital for joint assessment of candidates. Intestinal transplants in children are performed at the Birmingham Children's Hospital. Survival values are comparable with those reported in international series ${ }^{164}$ but to date only 14 adult patients have received intestinal grafts in this country. Compared with other European and North American transplant centres, fewer patients are referred for intestinal transplantation in the UK and often too late to consider the operation. ${ }^{165}$ As for all organ transplantation programmes, early discussion with a view to referral for assessment is essential. For instance, while lack of vascular access for intravenous nutrition is an indication of intestinal transplantation, it must be remembered that adequate central venous access is still required for a successful operative outcome. Furthermore, patients may have to wait a considerable length of time for donor organs to become available.

As outcomes of intestinal transplantation continue to improve, its indications will evolve, but the current major criteria for referral for consideration of intestinal transplantation are listed in table 7 .

\section{Authors' affiliations}

J M D Nightingale, St Mark's Hospital, Harrow, UK

J M Woodward, Addenbrooke's Hospital, Cambridge, UK

Conflict of interest: None declared.

\subsection{REFERENCES}

1 Eccles M, Clapp Z, Grimshaw J, et al. North of England evidence based guidelines project: methods of guideline development. BMJ 1996:312:760-2.

2 Nightingale JMD, Bartram Cl, Lennard-Jones JE. Length of residual small bowel after partial resection: Correlation between radiographic and surgical measurements. Gastrointest Radiol 1991;16:305-6.

3 Carbonnel F, Cosnes J, Chevret S, et al. The role of anatomic factors in nutritional autonomy after extensive small bowel resection. J Parenter Enteral Nutr 1996;20:275-80

4 Nightingale JMD. Introduction. Definition and classification of intestinal failure. In, Nightingale JMD, eds. Intestinal failure Greenwich, Greenwich Medical Media Limited, 2001:xix-xx.

5 Jeppesen PB, Mortensen PB. Intestinal failure defined by measurements of intestinal energy and wet weight absorption. Gut. 2000;46: 701-6 (erratum appeasrs in Gut, 2000;47:158).

6 Nightingale JMD. The medical management of intestinal failure: methods to reduce the severity. Proc Nutr Soc 2003;62:703-10.

7 Nightingale JMD, Lennard-Jones JE, Gerner DJ, et al. Colonic preservation reduces the need for parenteral therapy, increases the incidence of renal stones but does not change the high prevalence of gallstones in patients with a short bowel. Gut 1992;33:1493-7.

8 Gouttebel MC, Saint-Aubert B, Astre C, et al. Total parenteral nutrition needs in different types of short bowel syndrome. Dig Dis Sci 1986;31:718-23.

9 Simons BE, Jordan GL. Massive bowel resection. Am J Surg 1969;118:953-9.

10 Nightingale JMD, Kamm MA, van der Siip JRM, et al. Disturbed gastric emptying in the short bowel syndrome. Evidence for a "colonic brake". Gut 1993;34:1171-6.

11 Nightingale JMD, Kamm MA, van der Sijp JRM, et al. Gastrointestinal hormones in the short bowel syndrome. PYY may be the 'colonic brake' to gastric emptying. Gut 1996;39:267-72.

12 Jeppesen PB, Hartmann B, Thulesen J, et al. Elevated plasma glucagon-like peptide 1 and 2 concentrations in ileum-resected short bowel patients with a preserved colon. Gut 2000;47:370-6.

13 Jeppesen PB, Hartmann B, Hansen BS, et al. Impaired stimulated glucagonlike peptide 2 response in ileal resected short bowel patients with intestinal failure. Gut 1999;45:559-63.

14 Nightingale JMD, Lennard-Jones JE, Walker ER, et al. Jejunal efflux in short bowel syndrome. Lancet 1990;336:765-8.

15 Newton CR, Drury P, Gonvers JJ, et al. Incidence and treatment of sodium depletion in ileostomists. Scand J Gastroenterol 1982;74(suppl):159-60.

16 Windsor CWO, Fejfar J, Woodward DAK. Gastric secretion after massive small bowel resection. Gut 1969;10:779-86.

17 Booth CC, Mollin DL. The site of absorption of vitamin $B_{12}$ in man. Lancet 1959;i:18-21.

18 Booth CC. The metabolic effects of intestinal resection in man. Postgrad Med J 1961;37:725-39.

19 Booth CC, Alldis D, Read AE. Studies on the site of fat absorption: 2. Fat balances after resection of varying amounts of the small intestine in man. Gut $1961 ; 2: 168-74$.

20 Hessov I, Andersson H, Isaksson B. Effects of a low-fat diet on mineral absorption in small-bowel disease. Scand J Gastroenterol 1983;18:551-4.

21 Hanna S, Maclntyre I. The influence of aldosterone on magnesium metabolism. Lancet 1960;2:348-50.

22 Horton R, Biglieri EG. Effect of aldosterone on the metabolism of magnesium. J Clin Endocrinol Metab 1962;22:1 187-92.

23 Fatemi S, Ryzen E, Flores J, et al. Effect of experimental human magnesium depletion on parathyroid hormone secretion and 1,25 dihydroxyvitamin $D$ metabolism. J Clin Endocrinol Metab 1991;73:1067-72.

24 Zofkova I, Kancheva RL. The relationship between magnesium and calciotropic hormones. Magnes Res 1995;8:77-84. 
25 Crenn P, Beloucif L, Morin MC, et al. Adaptive hyperphagia and net digestive absorption in short bowel patients. Gastroenterology 1997; 112:A356.

26 Goodlad RA, Nightingale JMD, Playford RJ. Intestinal adaptation. In: Nightingale JMD, eds. Intestinal failure. Greenwich: Greenwich Medical Media Limited, 2001:243-60.

27 Porus RL. Epithelial hyperplasia following massive small bowel resection in man. Gastroenterology 1965:48:753-9.

28 De Francesco A, Malfi G, Delsedime L, et al. Histological findings regarding jejunal mucosa in short bowel syndrome. Transplant Proc 1994;26:1455-6.

29 Althausen TL, Doig RK, Uyeyama K, et al. Digestion and absorption after massive resection of the small intestine. II. Recovery of the absorptive function as shown by intestinal absorption tests in two patients and a consideration of compensatory mechanisms. Gastroenterology 1950;16:126-34.

30 Dowling RH, Booth CC. Functional compensation after small bowel resection in man: Demonstration by direct measurement. Lancet 1966;ii:146-7.

31 Cosnes J, Carbonnel F, Beaugerie L, et al. Functional adaptation after extensive small bowel resection in humans. Eur J Gastroenterol Hepatol 1994;6: 197-202.

32 Gouttebel MC Saint Aubert B Colette C et al Intestinal adaptation in patients with short bowel syndrome. Measurement by calcium absorption. Dig Dis Sci 1989;34:709-15.

33 Messing $B$, Crenn $P, B$ eau $P$, et al. Long-term survival and parenteral nutrition dependence in adult patients with the short bowel syndrome. Gastroenterology 1999;117:1043-50.

34 O'Keefe SJD, Haymond MW, Bennet WM, et al. Long-acting somatostatin analogue therapy and protein metabolism in patients with jejunostomies. Gastroenterology 1994;107:379-88.

35 Hill GL, Mair WSJ, Goligher JC. Impairment of 'ileostomy adaptation' in patients after ileal resection. Gut 1974;15:982-7.

36 Nightingale JMD, Walsh N, Bullock ME, et al. Comparison of three simple methods for the detection of malnutrition. J R Soc Med 1996;89:144-8.

37 Stratton RJ, Hackston A, Longmore D, et al. Malnutrition in hospital outpatients and inpatients: prevalence, concurrent validity and ease of use of the 'malnutrition universal screening tool' ('MUST') for adults. Br J Nutr 2004;92:799-808.

38 American Gastroenterological Association medical position statement. Short bowel syndrome and intestinal transplantation. Gastroenterology 2003; 124:1 105-10

39 Nightingale JMD. Gastrostomy placement in patients with Crohn's disease. Eur J Gastroenterol Hepatol 2000;12:1073-5.

40 Rodrigues CA, Lennard-Jones, Thompson DG, et al. Energy absorption as a measure of intestinal failure in the short bowel syndrome. Gut 1989;30:176-83.

41 Spiller RC, Brown ML, Phillips SF. Decreased fluid tolerance, accelerated transit, and abnormal motility of the human colon induced by oleic acid. Gastroenterology 1986;91:100-7

42 Ammon HV, Phillips SF. Inhibition of colonic water and electrolyte absorption by fatty acids in man. Gastroenterology 1973;65:744-9.

43 Knapp HR, Melly MA. Bactericidal effects of polyunsaturated fatty acids. J Infect Dis 1986; 154:84-94.

44 Andersson $\mathrm{H}$. The use of a low-fat diet in the symptomatic treatment of ileopathia. World Rev Nutr Diet 1982;40:1-18.

45 Ovesen L, Chu R, Howard L. The influence of dietary fat on jejunostomy output in patients with severe short bowel syndrome. Am J Clin Nutr 1983;38:270-7

46 Jeppesen PB, Christensen MS, Hoy CE, et al. Essential fatty acid deficiency in patients with severe fat malabsorption. Am J Clin Nutr 1997;65:837-43.

47 Press M, Hartop PJ, Prottey C. Correction of essential fatty-acid deficiency in man by cutaneous application of sunflower-seed oil. Lancet 1974;ii:597-9.

48 Zurier RB, Campbell RG, Hashim SA, et al. Use of medium-chain triglyceride in management of patients with massive resection of the small intestine. N Engl J Med 1966;274:490-3.

49 Bochenek W, Rodgers JB Jr, Balint JA. Effects of changes in dietary lipids on intestinal fluid loss in the short-bowel syndrome. Ann Intern Med 1970;72:205-13.

50 Tandon RK, Rodgers JB Jr, Balint JA. The effects of medium-chain triglycerides in the short bowel syndrome. Increased glucose and water transport. Am J Dig Dis 1972;17:233-8.

51 Jeppesen PB, Mortensen PB. The influence of a preserved colon on the absorption of medium chain fat in patients with small bowel resection. Gut 1998;43:478-83.

52 Nordgaard I, Hansen BS, Mortensen PB. Colon as a digestive organ in patients with short bowel. Lancet 1994;343:373-6.

53 Gruy-Kapral C, Little KH, Fortran JS, et al. Conjugated bile acid replacement therapy for short-bowel syndrome. Gastroenterology 1999;116:15-21.

54 Heydorn S, Jeppesen PB, Mortensen PB. Bile acid replacement therapy with cholylsarcosine for short-bowel syndrome. Scand J Gastroenterol 1999;34:818-23.

55 Ladefoged K, Ølgaard K. Fluid and electrolyte absorption and reninangiotensin-aldosterone axis in patients with severe short-bowel syndrome. Scand J Gastroenterol 1979;14:729-35.

56 Ladefoged K, Ølgaard K. Sodium homeostasis after small-bowel resection. Scand J Gastroenterol 1985;20:361-9.

57 Davis AT, Franz FP, Courtnay DA, et al. Plasma and mineral status in home parenteral nutrition patients. J Parenter Enteral Nutr 1987;11:480-5.

58 Shenkin A, Fell GS, Halls DJ, et al. Essential trace element provision to patients receiving home intravenous nutrition in the United Kingdom. Clin Nutr 1986:5:91-7.
59 Rannem T, Ladefoged K, Hylander E, et al. Selenium depletion in patients on home parenteral nutrition. The effect of selenium supplementation. Biol Trace Element Res 1993;39:81-90.

60 Rannem T, Hylander $\mathrm{E}$, Ladefoged $\mathrm{K}$, et al. The metabolism of $\left.\mathrm{F}^{75} \mathrm{Se}\right]$ selenite in patients with short bowel syndrome. J Parenter Enteral Nutr 1996;20:412-16.

61 Wolman SL, Anderspon GH, Marliss EB, et al. Zinc in total parenteral nutrition: requirements and metabolic effects. Gastroenterology 1979.76:458-67.

62 Hofmann AF, Poley JR. Role of bile acid malabsorption in the pathogenesis of diarrhoea and steatorrhoea in patients with ileal resection. I. Response to cholestyramine or replacement of dietary long chain triglyceride by medium chain triglycerides. Gastroenterology 1972;62:918-34.

63 Editorial. The colon, the rumen, and D-lactic acidosis. Lancet 1990;336:599-600

64 Mayne AJ, Handy DJ, Preece MA, et al. Dietary management of D-lactic acidosis in short bowel syndrome. Arch Dis Child 1990;65:229-31.

65 Yamada E, Wakabayashi Y, Saito A, et al. Hyperammonaemia caused by essential aminoacid supplements in patient with short bowel. Lancet 1993;341:1542-3.

66 Yokoyama K, Ogura Y, Kawabata M, et al. Hyperammonemia in a patient with short bowel syndrome and chronic renal failure. Nephron 1996;72:693-5

67 Brophy DF, Ford SL Crouch MA. Warfarin resistance in a patient with short bowel syndrome. Pharmacotherapy 1998;18:646-9.

68 Ehrenpreis ED, Guerriero S, Nogueras JJ, et al. Malabsorption of digoxin tablets, gel caps, and elixir in a patient with an end jejunostomy. Ann Pharmacotherap 1994;28:1239-40.

69 Nealon WH, Upp JR, Alexander RW, et al. Intravenous amino acids stimulate human gallbladder emptying and hormone release. Am J Physiol 1990:259:G173-8

70 Doty JE, Pitt HA, Porter-Fink V, et al. Cholecystokinin prophylaxis of parenteral nutrition-induced gallbladder disease. Ann Surg 1985:201:76-80

71 Lee SP, Carey MC, LaMont JT. Aspirin prevention of cholesterol gallstone formation in prairie dogs. Science 1981;211:1429-31.

72 O'Donnell UD, Wilson P, Guest $P$, et al. Indomethacin and post-prandial gallbladder emptying. Lancet 1992;339:269-71.

73 Williams C, Gowan R, Perey BJ. A double-blind placebo-controlled trial of ursodeoxycholic acid in the prevention of gallstones during weight loss after vertical banded gastroplasty. Obes Surg 1993;3:257-9.

74 Hussaini SH, Pereira SP, Dowling RH, et al. Slow intestinal transit and gallstone formation. Lancet 1993;341:638.

75 Capron J-P, Gineston J-L, Herve M-A, et al. Metronidazole in prevention of cholestasis associated with total parenteral nutrition. Lancet 1983;i:446-7.

76 Thompson JS. The role of prophylactic cholecystetomy in the short bowel syndrome. Arch Surg 1996;131:556-60.

77 Chadwick VS, Modha K, Dowling RH. Mechanism for hyperoxaluria in patients with ileal dysfunction. N Engl J Med 1973;289:172-6.

78 Stauffer JQ, Humphreys MH, Weir GJ. Acquired hyperoxaluria with regional enteritis after ileal resection. Role of dietary oxalate. Ann Intern Med 1973:79:383-91.

79 Earnest DL, Johnson G, Williams HE, et al. Hyperoxaluria in patients with ileal resection: an abnormality in dietary oxalate absorption. Gastroenterology 1974;66:1114-22.

80 Dobbins JW, Binder HJ. Importance of the colon in enteric hyperoxaluria. N Engl J Med 1977;296:298-301.

81 Tomson CRV. Nephrocalcinosis and nephrolithiasis. In: Nightingale JMD eds. Intestinal failure. Greenwich: Greenwich Medical Media Limited, 2001:227-42

82 Rudman D, Dedonis JL, Fountain MT, et al. Hypocitraturia in patients with gastrointestinal malabsorption. N Engl J Med 1980;303:657-61

83 AGA Technical review on short bowel syndrome and intestinal transplantation. Gastroenterology 2003;124:1111-34.

84 Earnest DL, Williams HE, Admirand WH. A physicochemical basis for treatment of enteric hyperoxaluria. Trans Assoc Am Physicians 1975;88:224-34

85 Caspary WF, Tonissen J, Lankisch PG. Enteral hyperoxaluria. Effect of cholestyramine, calcium, neomycin, and bile acids on intestinal oxalate absorption in man. Acta Hepatogastroenterol (Stuttg) 1977;24:193-200.

86 Barilla DE, Notz C, Kennedy D, et al. Renal oxalate excretion following oral oxalate loads in patients with ileal disease and with renal and absorptive hypercalciurias. Effect of calcium and magnesium. Am J Med 1978;64:579-85.

87 Lindsjo M, Fellstrom B, Ljunghall S, et al. Treatment of enteric hyperoxaluria with calcium-containing organic marine hydrocolloid. Lancet 1989;ii:701-4.

88 Smith LH, Fromm H, Hofmann AF. Acquired hyperoxaluria, nephrocalcinosis, and intestinal disease. Description of a syndrome. NEngl J Med 1972;286:1371-5.

89 Whang $\mathbf{R}$, Whang DD, Ryan MP. Refactory potassium repletion. A consequence of magnesium deficiency. Arch Intern Med 1992;152:40-5.

90 Solomon $\mathbf{R}$. The relationship between disorders of $\mathrm{K}^{+}$and $\mathrm{Mg}^{+}$homeostasis. Semin Nephrol 1987;7:253-62.

91 Newton CR, Drury P, Gonvers JJ, et al. Incidence and treatment of sodium depletion in ileostomists. Scand J Gastroenterol 1982;74(suppl): 159-60.

92 Griffin GE, Fagan EF, Hodgson HJ, et al. Enteral therapy in the management of massive gut resection complicated by chronic fluid and electrolyte depletion. Dig Dis Sci 1982;27:902-8.

93 Kennedy HJ, Al-Dujaili EAS, Edwards CRW, et al. Water and electrolyte balance in subjects with a permanent ileostomy. Gut 1983:24:702-5. 
94 Newton CR, Gonvers JJ, Mclntyre PB, et al. Effect of different drinks on fluid and electrolyte losses from a jejunostomy. J R Soc Med 1985;78:27-34.

95 Rodrigues CA, Lennard-Jones JE, Thompson DG, et al. What is the ideal sodium concentration of oral rehydration solutions for short bowel patients? Clin Sci 1988;74(suppl 18):69.

96 Nightingale JMD, Lennard-Jones JE, Walker ER, et al. Oral salt supplements to compensate for jejunostomy losses: comparison of sodium chloride capsules, glucose electrolyte solution and glucose polymer electrolyte solution (Maxijul). Gut 1992;33:759-61.

97 Woolf GM, Miller C, Kurian R, et al. Nutritional absorption in short bowel syndrome. Evaluation of fluid, calorie and divalent cation requirements. Dig Dis Sci 1987;32:8-15.

98 Olsen WA, Ingelfinger FJ. The role of sodium in intestinal glucose absorption in man. J Clin Invest 1968:47:1133-42.

99 Sladen GE, Dawson AM. Interrelationships between the absorptions of glucose, sodium and water by the normal human jejunum. Clin $\mathrm{Sci}$ 1969;36:119-32.

100 Fordtran JS. Stimulation of active and passive sodium absorption by sugars in the human jejunum. J Clin Invest 1975;55:728-37.

101 Avery ME, Snyder JD. Oral therapy for acute diarrhoea. The underused simple solution. N Engl J Med 1990;323:891-94.

102 Newton CR. Effect of codeine phosphate, Lomotil and Isogel on ileostomy function. Gut 1978;19:377-83.

103 King RFGJ, Norton T, Hill GL. A double-blind crossover study of the effect of loperamide hydrochloride and codeine phosphate on ileostomy output. Aust NZ J Surg 1982;52:121-4.

104 Tytgat GN, Huibregtse K. Loperamide and ileostomy output-placebocontrolled double-blind crossover study. BMJ 1975;2:667-8.

105 Tytgat GN, Huibregtse K, Dagevos J, et al. Effect of loperamide on fecal output and composition in well-established ileostomy and ileorectal anastomosis. Dig Dis 1977;22:669-76.

106 Nightingale JMD, Lennard-Jones JE, Walker ER. A patient with jejunostomy liberated from home intravenous therapy after 14 years; contribution of balance studies. Clin Nutr 1992;11:101-5.

107 Aly A, Barany F, Kollberg B, et al. Effect of an $\mathrm{H}_{2}$-receptor blocking agent on diarrhoeas after extensive small bowel resection in Crohn's disease. Acta Med Scand 1980;207:119-22.

108 Jacobsen O, Ladefoged K, Stage JG, et al. Effects of cimetidine on jejunostomy effluents in patients with severe short bowel syndrome. Scand J Gastroenterol 1986:21:824-8.

109 Nightingale JMD, Walker ER, Farthing MJG, et al. Effect of omeprazole on intestinal output in the short bowel syndrome. Aliment Pharmacol Therap $1991 ; 5: 405-12$

110 Jeppesen PB, Staun M, Tjellesen L, et al. Effect of intravenous ranitidine and omeprazole on intestinal absorption of water, sodium, macronutrients in patients with intestinal resection. Gut 1998;43:763-9.

111 Rodrigues CA, Lennard-Jones JE, Walker ER, et al. The effects of octreotide, soy polysaccharide, codeine and loperamide on nutrient, fluid and electrolyte absorption in the short bowel syndrome. Aliment Pharmacol Ther 1989:3:159-69

112 Cooper JC, Williams NS, King RFGJ, et al. Effects of a long acting somatostatin analogue in patients with severe ileostomy diarrhoea. $\mathrm{Br} J$ Surg 1986;73:128-31

113 Kusuhara K, Kusunoki M, Okamoto T, et al. Reduction of the effluent volume in high-output ileostomy patients by a somatostatin analogue, SMS 201995. Int J Colorect Dis 1992;7:202-5.

114 Shaffer JL, O'Hanrahan T, Rowntree S, et al. Does somatostatin analogue (201-995) reduce high output stoma effluent? A controlled trial. Gut 1988;29:A1432-3.

115 Nightingale JMD, Walker ER, Burnham WR, et al. Octreotide (a somatostatin analogue) improves the quality of life in some patients with a short intestine. Aliment Pharmacol Therap 1989;3:367-73.

116 Nightingale JMD. The Sir David Cuthbertson Medal Lecture. Clinical problems of a short bowel and their treatment. Proc Nutr Soc 1994:53:373-91.

117 Ladefoged K, Christensen KC, Hegnhoj J, et al. Effect of a long acting somatostatin analogue SMS 201-995 on jejunostomy effluents in patients with severe short bowel syndrome. Gut 1989;30:943-9.

118 Lémann M, de Montigny S, Mahé S, et al. Effect of octreotide on water and electrolytes losses, nutrient absorption and transit in short bowel syndrome. Eur J Gastroenterol Hepatol 1993;5:817-22.

119 O'Keefe SJD, Peterson ME, Fleming R. Octreotide as an adjunct to home parenteral nutrition in the management of permanent end-jejunostomy syndrome. J Parenter Enteral Nutr 1994;18:26-34.

120 Nehra V, Camilleri M, Burton D, et al. An open trial of octreotide long-acting release in the management of short bowel syndrome. Am J Gastroenterol 2001;96:1494-8.

121 Goulston K, Harrison DD, Skyring AP. Effect of mineralocorticoids on the sodium/potassium ratio of human ileostomy fluid. Lancet 1963;ii:541-3.

122 Levitan R, Goulston K. Water and electrolyte content of human ileostomy fluid after d-aldosterone administration. Gastroenterology 1967:52:510-12.

123 Kramer P, Levitan R. Effect of $9 \alpha$-fludrocortisone on the ileal excreta of ileostomized subjects. Gastroenterology 1972;62:235-41.

124 Feretis CB, Vyssoulis GP, Pararas BN, et al. The influence of corticosteroids on ileostomy discharge of patients operated for ulcerative colitis. Am Surg 1984;50:433-6.

125 Martinez-Riquelme A, Rawlings J, Morley S, et al. Self-administered subcutaneous fluid infusion at home in the management of fluid depletion and hypomagnesaemia in gastro-intestinal disease. Clin Nutr 2005;24:158-63.
126 Selby PL, Peacock M, Bambach CP. Hypomagnesaemia after small bowel resection: treatment with 1 alpha-hydroxylated vitamin $D$ metabolites. Br J Surg 1984;71:334-7

127 Fukumoto S, Matsumoto T, Tanaka Y, et al. Renal magnesium wasting in a patient with short bowel syndrome with magnesium deficiency: effect of $1 \alpha$-hydroxyvitamin $D_{3}$ treatment. J Clin Endocrinol Metab 1987;65:1301-4.

128 Mclntyre PB, Fitchew M, Lennard-Jones JE. Patients with a jejunostomy do not need a special diet. Gastroenterology 1986;91:25-33.

129 Woolf GM, Miller C, Kurian R, et al. Diet for patients with a short bowel: high fat or high carbohydrate? Gastroenterology 1983;84:823-8.

130 Ellegard L, Bosaeus I, Nordgren S, et al. Low-dose recombinant growth hormone increases body weight and lean body mass in patients with short bowel syndrome. Ann Surg 1997;225:88-96.

131 Scolapio JS, Camilleri M, Fleming CR, et al. Effect of growth hormone, glutamine, and diet on adaptation in short-bowel syndrome: a randomized, controlled study. Gastroenterology, 1997;113;1074-81.

132 Szkudlarek J, Jeppesen PB, Mortensen PB. Effect of high dose growth hormone with glutamine and no change in diet on intestinal absorption in short bowel patients: a randomised, double blind, crossover, placebo controlled study. Gut 2000;47:199-205

133 Seguy D, Vahedi K, Kapel N, et al. Low-dose growth hormone in adult home parenteral nutrition-dependent short bowel syndrome patients: a positive study. Gastroenterology 2003;124:293-302.

134 Jeppesen PB, Hartmann B, Thulesen J, et al. Glucagon-like peptide 2 improves nutrient absorption and nutritional status in short bowel patients with no colon. Gastroenterology 2001;120:806-15.

135 Jeppesen PB, Sanguinetti EL, Buchman A, et al. Teduglutide (ALX-0600), a dipeptidyl peptidase IV resistant glucagon-like peptide 2 analogue, improves intestinal function in short bowel syndrome patients. Gut 2005;54:1224-31.

136 Shanbhogue LKR, Molenaar JC. Short bowel syndrome: metabolic and surgical management. Br J Surg 1994;81:486-99.

137 Thompson JS. Surgery for patients with a short bowel. In: Nightingale JMD, eds. Intestinal failure. Greenwich: Greenwich Medical Media Limited, 2001:515-27.

138 Mughal M, Irving M. Home parenteral nutrition in the United Kingdom and Ireland. Lancet 1986;200:383-6.

139 Stokes MA, Irving M. Mortality in patients on home parenteral nutrition. J Parenter Enteral Nutr 1989;13:172-5.

140 Messing B, Landais P, Goldfarb B, et al. Home parenteral nutrition in adults: a multicentre survey in Europe. Clin Nutr 1989;8:3-9.

141 Messing $B$, Lèman $M$, Landais $P$, et al. Prognosis of patients with nonmalignant chronic intestinal failure receiving long-term home parenteral nutrition. Gastroenterology 1995; 108:1005-10.

142 Van Gossum A. ESPEN-HAN group. Home parenteral nutrition (HPN) in adults: a multicentre survey in Europe in 1993, Clin Nutr 1996;15:53-8.

143 Scolapio SJ, Fleming CR, Kelly DG, et al. Survival of home parenteral nutrition-treated patients: 20 years of experience at the Mayo Clinic. Mayo Clinic Proc 1999:74:217-22.

144 Van Gossum A, Bakker H, Bozzetti F, et al. Home parenteral nutrition in adults: a European multicentre survey in 1997. Clin Nutr 1999;18:135-40.

145 Pironi L, Paganelli P, Morselli LAM, et al. Safety and efficacy of home parenteral nutrition for chronic intestinal failure: a 16 year experience at a single centre. Dig Liver Dis 2003;35:314-24.

146 Woodward JM, Mayer AD. The unique challenge of small intestinal transplantation. Br J Hosp Med 1996;56:285-90.

147 Intestinal transplant registry. http:// www.intestinaltransplantregistry@uhn.on.ca.

148 Cameron EA, Binnie JA, Jamieson NV, et al. Quality of life in adults following small bowel transplantation. Transplantation Proc 2002;34:965-6.

149 Messing B, Crenn P, Beau P, et al. Long term survival and parenteral nutrition dependence in adult patients with the short bowel syndrome. Gastroenterology 1999; 117:1043-50.

150 Jeppesen PB, Staun M, Mortensen PB. Adult patients receiving home parenteral nutrition in Denmark from 1991-1996: who will benefit from intestinal transplantation? Scand J Gastroenterol 1998;338:839-46.

151 Bozzetti F, Mariani L, Boggio BD, et al. EPSEN-HAN working group. Central venous catheter complications in 447 patients on home paraenteral nutrition: an analysis of over 100000 catheter days, Clin Nutr 2002;21:475-85.

152 Hayden L, Stewart GR, Johnson DC, et al. Transthoracic right atria cannulation for total parenteral nutrition. Anaesth Intensive Care $1981 ; 9: 53-7$

153 Lammermeier D, Steiger E, Cosgrove D. Use of an intercostal vein for central vascular access in home parenteral nutrition: a case report. J Parenter Enteral Nutr 1986;10:659-61.

154 Buchman AL, Misra SS, Moukarzel A, et al. Catheter thrombosis and superior/inferior vena cava syndrome are rare complications of long term parenteral nutrition. Clin Nutr 1994;13:356-60

155 Turner SM, Probert CSJ, Lear P. Parenteral nutrition via an arteriovenous bypass graft. Gut 2003:52:1218.

156 Clarke PJ, Ball MJ, Kettelwell MG. Liver function tests in patients receiving parenteral nutrition. J Parenter Enteral Nutr 1991;15:54-9.

157 Ito $Y$, Shils ME. Liver dysfunction associated with long term total parenteral nutrition in patients with massive bowel resection. J Parenter Enteral Nutr $1991 ; 15: 271-6$.

158 Quigley EMM, Marsh MN, Schaffer JL, et al. Hepatobiliary complications of total parenteral nutrition. Gastroenterology 1993;104:286-301.

159 Nightingale JMD. Hepatobiliary, renal and bone complications of intestinal failure. Best Pract Res Clin Gastroenterol 2003;17:907-29. 
160 O'Keefe SJD, Burnes JU, Thompson RL. Recurrent sepsis in home parenteral nutrition patients: an analysis of risk factors. J Parenter Enteral Nutr 1994;18:256-63.

161 Richards DM, Scott NA, Shaffer J, et al. Opiate and sedative dependence predicts a poor outcome for patients receiving home parenteral nutrition. $J$ Parenter Enteral Nutr 1997;21:336-8.

162 Luman W, Schaffer J. Prevalence, outcome and associated factors of deranged liver function tests in patients on home parenteral nutrition. Clin Nutr 2002;21:337-43
163 Cavicchi $M$, Beau P, Crenn P, et al. Prevalence of liver disease and contributing factors in patients receiving home parenteral nutrition for permanent intestinal failure. Ann Intern Med 2000;132:525-32.

164 Middleton SJ, Pollard S, Friend PJ, et al. Adult small intestinal transplantation in England and Wales. Br J Surg 2003:90:723-7.

165 Middleton SJ, Jamieson NV. The current status of small bowel transplantation in the UK and Internationally. Gut 2005;54:1650-7. 